\title{
Governança Corporativa: Fator Preponderante no Ativismo de Acionistas no Brasil
}

\author{
Corporate Governance: A Major Factor in Shareholder Activism in Brazil
}

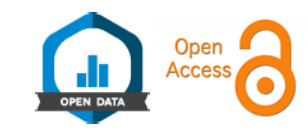

Marta Leite Collares ${ }^{1}$

\section{RESUMO}

Objetivo: este trabalho verificou a relação entre o ativismo de acionistas e os elementos de governança corporativa e desempenho financeiro das empresas brasileiras selecionadas, articulando a teoria da agência e o conceito voice da teoria exit, voice, and loyalty. Métodos: o ativismo foi apurado por um índice constituído pelo somatório de suas ocorrências, observadas nas atas das assembleias de 2016 e 2017 das cem empresas de capital aberto da amostra. Fatores de governança e desempenho corresponderam aos anos de 2015 e 2016, coletados via Economática ${ }^{\circledR}$. Aplicou-se a regressão quantílica (RQ) e os resultados foram comparados com a regressão por mínimos quadrados ordinários (MQO). Resultados: houve melhor adequação da RQ frente ao método de MQO, sugerindo que a governança afeta negativamente o ativismo e que seus efeitos são heterogêneos nas diferentes partes de sua distribuição. Resultados inconclusivos foram obtidos para variáveis de desempenho. Testes de robustez indicaram melhor capacidade explicativa para observações de ativismo em empresas posicionadas nos últimos 20\% mais altos do índice. Conclusão: foram encontradas evidências significativas de relação entre ativismo e governança, o que não ocorre de forma conclusiva com relação a desempenho, revelando o predomínio da primeira variável.

Palavras-chave: ativismo de acionistas; governança corporativa; regressão quantílica; teoria da agência.

Classificação JEL: G3, G2, N26.

\footnotetext{
${ }^{1}$ Universidade Federal do Rio de Janeiro, Instituto de Pós-Graduação e Pesquisa em Administração (COPPEAD), Rio de Janeiro, RJ, Brasil.
}

Como citar: Collares, M. L. (2020). Corporate governance: A major factor in shareholder activism in Brazil. Revista de Administração Confemporânea, 24(5), 414-431. https://doi.org/10.1590/1982-7849rac2020190338

\section{ABSTRACT}

Objective: This paper verified the relationship between shareholder activism and the elements of corporate governance and financial performance of selected Brazilian companies, articulating the agency theory and the voice concept from the exit, voice and loyalty theory. Methods: Activism was determined by a score constituted by the sum of its occurrences, observed in the minutes of the 2016 and 2017 general meetings of the 100 public companies in the sample. Governance and performance factors corresponded to 2015 and 2016, collected from Economática ${ }^{\circledR}$. Quantile regressions $(\mathrm{QR})$ were applied and the results were compared with ordinary least squares regressions (OLS). Results: there was a better adjustment of QR compared to the OLS method, suggesting that governance negatively affects activism and that its effects are heterogeneous in different parts of its distribution. Inconclusive results were obtained for performance variables. Robustness tests indicated better explanatory ability for activism observations in companies positioned in the last $20 \%$ of the activism indicator's distribution. Conclusion: significant evidence of a relationship between activism and governance was found, which does not occur conclusively in relation to performance, revealing the predominance of the first variable.

Keywords: shareholder activism; corporate governance; quantile regression; agency theory.

\begin{tabular}{|c|c|c|c|c|c|c|c|c|c|}
\hline & 1 & 2 & 3 & 4 & 5 & 6 & 7 & 8 & 9 \\
\hline $1^{a}$ rodada & $x$ & $x$ & $\stackrel{9}{2}$ & 2 & & & & & \\
\hline $2^{a}$ rodada & 2 & & & & & & & & \\
\hline $3^{a}$ rodada & $\stackrel{9}{2}$ & & & & & & & & \\
\hline
\end{tabular}

Editor-chefe: Wesley Mendes-Da-Silva (Fundação Getulio Vargas, EAESP, Brasil) Pareceristas: Antonio Zoratto Sanvicente (Fundação Getulio Vargas, EESP, Brasil) Valcemiro Nossa (Fucape Business School, Brasil) 다

Recebido em: 12/10/2019 Última versão recebida em: 07/04/2020 Aceite em: 07/04/2020 


\section{INTRODUÇÃO}

A participação de acionistas em movimentos explícitos que visam a influenciar as políticas e práticas corporativas nas empresas nas quais investem é um fenômeno internacionalmente vivenciado pelos mercados de capitais, tendo sido disseminado pelo processo de globalização do capital financeiro, que ampliou as fronteiras de investimentos aos investidores institucionais (Gillan \& Starks, 2003; Goranova \& Ryan, 2014).

A potencialidade dos efeitos deste movimento nos mercados pode ser dimensionada pelo montante de aproximadamente US\$ 65 bilhões empregados em campanhas globais por investidores ativistas durante 2018 (Harvard Law School Forum on Corporate Governance and Financial Regulation [HLS], 2019), equivalente ao mercado de capitais de Portugal (US\$ 62 bilhões) naquele mesmo ano (World Bank Group, 2019). Dentre os resultados desse esforço em intervir na gestão das companhias, temos: aumento da representatividade no conselho de administração, sucesso na indicação de CEO e interrupção de processos de fusões e aquisições (mergers and acquisitions - M\&A). Fruto de um total de 247 campanhas, tais resultados não se refletiram exclusivamente em empresas americanas: 43\% delas (106) foram direcionadas ao mercado global, tendo quatro campanhas atingido três empresas brasileiras (Stenco, Petrobras e Oi) (HLS, 2019).

A presença de empresas nacionais dentre alvos de campanhas ativistas internacionais em relatórios especializados (Activist Insight, 2019; HLS, 2019) e a existência de diretrizes que orientam a votação em assembleias no Brasil (Institutional Shareholder Service [ISS], 2018) emitidas por shareholder advisories podem indicar a relevância do fenômeno nas organizações brasileiras. Somamse a esses indícios as ocorrências de situações de conflito mediadas por ações associadas ao ativismo de acionistas veiculadas em mídia especializada, como notas do jornal Valor Econômico sobre eventos ocorridos nos dois últimos anos na CCR (Azevedo, 2019) e Qualicorp (Valenti \& Schincariol, 2018), as deliberações e análises do órgão regulador brasileiro, Comissão de Valores Mobiliários (CVM), e as orientações e comunicados das entidades representativas dos integrantes do mercado de capitais e daquelas orientadas ao estímulo de boas práticas de governança.

As ações de ativismo de acionistas no ambiente brasileiro de negócios constituem um conjunto de evidências suficiente para ensejar pesquisas acadêmicas que permitam melhor conhecer o fenômeno e seus impactos. Dentre as possibilidades permitidas pelo complexo tema e visando a contribuir para uma convergência no seu entendimento, este trabalho se empenhou em verificar as relações entre o ativismo e: (a) a qualidade de governança corporativa (GC) e (b) o desempenho das empresas selecionadas no mercado brasileiro de capitais. Foram consideradas as ações ativistas dos acionistas manifestadas nas assembleias gerais (ordinárias e extraordinárias) nos anos de 2016 e 2017. Ressaltase que o estudo não aspirou a estabelecer a relação causal inequívoca entre os termos acima descritos, mas sim explorar as relações considerando seu efeito diferenciado nas empresas da amostra, a partir de um método inovador (regressão quantílica) para o tema proposto, ampliando as possibilidades de análise.

A fundamentação teórica do ativismo de acionistas tem sido associada à teoria do agente (Jensen \& Meckling, 1976) por expor o clássico conflito acionistas-gestores e por ampliá-lo, englobando as relações entre acionistas majoritários e minoritários. O ativismo se articula com o sistema de GC na medida em que utiliza seus recursos e estruturas objetivando a minimização de conflitos e a garantia de retornos de seus investimentos (La Porta, Lopez-de-Silanes, Shleifer, \& Vishny, 2000; Shleifer \& Vishny, 1997), e se manifesta por meio de três possibilidades de ação (Hirschman, 1970): venda de suas ações (exit), movimentação ativa para garantia de direitos (voice) e manutenção passiva de suas ações (loyalty). Amplia-se a visão sobre o ativismo considerando a motivação por questões sociais - stakeholder activism - que coexiste com a literatura sobre o tema (Aguilera, Desender, Bednar, \& Lee, 2015).

Pesquisas empíricas têm abordado o tema por diversos aspectos, tais como: motivação, antecedentes, processos e resultados (Goranova \& Ryan, 2014) demonstrando, porém, pouco consenso sobre as relações de causa e efeito, o que pode estar associado a dificuldades com relação à heterogeneidade dos ativistas e seus objetivos (Brav, Jiang, Partnoy, \& Thomas, 2008; González \& Calluzzo, 2019) e a seus diferentes mecanismos de ação (Aguilera et al., 2015), assim como a suas ações não observáveis (McCahery, Sautner, \& Starks, 2015).

Estudos anteriores como os de Gillan e Starks (2003; 2007) defendem que ocorre melhoria dos mecanismos de governança pela ação de acionistas ativistas, assim como McNulty e Nordberg (2016) entendem que a figura do investidor engajado (active ownership) produzirá o mesmo efeito. Por outro lado, algumas pesquisas apresentam resultados ora com fraco relacionamento entre tais fatores (Elst, 2012), ora em sentido contrário (Punsuvo, Kayo, \& Barros, 2007; Vargas, Bortolon, Barros, \& Leal, 2017).

Com relação ao ativismo de acionistas e o desempenho das empresas-alvo, observam- 
se resultados contrastantes: enquanto alguns trabalhos reportaram aumento do valor da firma quando da adoção de melhor GC e maior ativismo de investidores (Brav et al., 2008; Cuñat, Gine, \& Guadalupe, 2012; Denes, Karpoff, \& McWilliams, 2017; González \& Calluzzo, 2019), outros, voltados para o ambiente nacional, apresentaram resultados inconclusivos (Brandão \& Crisóstomo, 2015; Pereira, 2010; Xavier, Marcon, Lana, \& Silva, 2013).

Para abordar os aspectos do ativismogovernança e ativismo-desempenho, foi utilizado o método de regressão quantílica (RQ), considerando ser este mais abrangente na análise da possível heterogeneidade das relações entre as variáveis (Conyon \& He, 2017; Prazeres, 2018; Shawatari, Salem, Hussain, Alaeddin, \& Thabit, 2016).

Diferentemente do modelo de regressão por mínimos quadrados ordinários (MQO), a RQ trabalha a minimização por programação linear (Koenker, 2005), oferecendo resultados que permitiriam responder às seguintes hipóteses:

Hipótese 1: há um efeito significativamente menor das ações de ativismo de acionistas nas empresas com melhor GC do que nas de pior GC.

Hipótese 2: há um efeito significativamente maior das ações de ativismo de acionistas nas empresas com pior desempenho do que nas que apresentam melhor desempenho.

Uma vez evidenciado o ativismo pela apuração de um índice (IAAA), procurou-se relacionar este índice às variáveis de governança e desempenho da amostra selecionada. A aplicação do modelo de regressão pelo método MQO se mostrou menos adequada, enquanto a RQ apresentou resultados mais adequados, confirmando o argumento da heterogeneidade dos efeitos.

Com relação ao elemento de GC, os resultados sugerem que quanto maior o número de membros independentes nos conselhos de administração, menor será a ocorrência de ativismo, indicando a importância deste mecanismo de GC. No que tange à relação entre o fenômeno e as variáveis de desempenho, não foi possível confirmar a Hipótese 2 , já que os resultados se mostraram inconclusivos.

Esta pesquisa contribui para o melhor entendimento da relação entre ativismo de acionistas e GC no contexto nacional, onde ainda se observam escassos trabalhos. Adicionalmente oferece, ao ambiente de negócios e de regulação, elementos para verificação do comportamento de ativistas frente à ampliação de seus direitos de participação em assembleias.

\section{REVISÃO DE LITERATURA}

\section{Governança corporativa}

A teoria da agência estruturada por Jensen e Meckling (1976) a partir de seus estudos com relação aos direitos de propriedade, custos de agência e teoria de finanças é pano de fundo deste estudo. Sobre ele serão tratados os aspectos ligados à GC. A lógica desta teoria prevê que os proprietários das empresas se relacionem conflituosamente com os administradores contratados gerando potenciais custos e que, para a minimização de tais problemas, são necessárias ações envolvendo o monitoramento de seus gerentes corporativos e a liberação de incentivos para estes gerentes. Assim, os acionistas teriam seus interesses e participações protegidos (Goranova \& Ryan, 2015).

A forma pela qual as empresas logram se estruturar com o objetivo de minimizar os problemas de agência é denominada governança corporativa. Não obstante a diversidade de definições de GC, para efeitos deste trabalho, ela é entendida como o sistema que lida com os meios pelos quais os acionistas asseguram o retorno de seus próprios investimentos (Shleifer \& Vishny, 1997). Largamente estudado na academia, entende-se que tal sistema é dotado de mecanismos que respondem às pressões externas e internas. Uma vez eficientemente empregados, esses mecanismos deverão produzir o alinhamento entre administradores e acionistas, provocando uma melhoria no desempenho da empresa (Aguilera et al., 2015). Desta forma, materializa-se o processo que pressupõe a retroalimentação das ações de monitoramento, recompensa e retorno.

Dentre os estudos associados às questões ligadas às pressões externas, há os que tratam do ambiente legal e regulatório e seu papel na estruturação dos perfis de governança e níveis de proteção aos investidores (Berglöf \& Claessens, 2006; La Porta, Lopez-de-Silanes, Shleifer, \& Vishny, 1998), que são complementados por aqueles mais recentes que procuram discutir a GC em termos comparativos ao nível das firmas, das nações e das relações entre elas (Aguilera, Marano, \& Haxhi, 2019; Schiehll, Ahmadjian, \& Filatotchev, 2014; Schiehll \& Martins, 2016). O papel do ambiente de negócios é investigado pelas pesquisas sob a ótica do mercado de controle (García-Castro, Aguilera, \& Ariño, 2013; Shleifer \& Vishny, 1997) e do papel dos investidores institucionais (Agrawal, 2012; García-Meca, LópezIturriaga, \& Tejerina-Gaite, 2017) buscando verificar os efeitos nas organizações e seus respectivos desempenhos.

Aspectos relacionados aos mecanismos internos de governança, correspondentes às pressões originadas dentro das organizações, têm sido estudados e enfocam, com frequência, temas como 
a estrutura da propriedade acionária (Carvalhal, 2012; González \& García-Meca, 2014), os conselhos de administração (Conyon \& He, 2017; Santos, Orso, Lizote, \& Marcon, 2018) e os incentivos aos administradores (Pinto \& Leal, 2013). Além disso, observam-se estudos que procuram mensurar os níveis de governança frente a possíveis resultados (Gompers, Ishii, \& Metrick, 2003; Leal, Carvalhalda-Silva, \& Iervolino, 2015) por meio de estudos longitudinais, que pretendem dar a medida da evolução deste sistema nas empresas.

Trabalhos acadêmicos buscam dar respostas às questões de causalidade e endogeneidade em GC (Aggarwal, Erel, Ferreira, \& Matos, 2011; GarcíaMeca et al., 2017; Silveira, Leal, Carvalhal-da-Silva, \& Barros, 2010). Aguilera, Desender, Bednar e Lee (2015) apresentam a discussão sobre a GC como um fator exógeno ou endógeno. Por outro lado, estudos não menos relevantes (Conyon \& He, 2017; Cuñat et al., 2012; García-Castro et al., 2013) contribuíram para o conhecimento abordando o tema por outros ângulos, formulando modelos teóricos ou utilizando métodos diferenciados (nos três últimos trabalhos citados, foram utilizados, respectivamente: regressão quantílica, fuzzy e regressão descontinuada), não necessariamente buscando estabelecer tal relação.

No Brasil, atentos à disseminação da GC, pesquisadores elaboraram estudos com o intuito de verificar as múltiplas características e efeitos desse sistema sobre o ambiente de negócios nacional. Sendo uma das principais características das empresas brasileiras seu perfil de concentração de propriedade, diversos estudos sobre esta questão foram realizados, destacando-se dentre eles os de Carvalhal (2012), Brandão e Crisóstomo (2015), Saito e Silveira (2008), Sonza e Kloeckner (2014), e Valadares e Leal (2000), que evidenciam - entre outras conclusões - os conflitos entre acionistas majoritários e minoritários.

\section{Ativismo de acionistas}

Entendido como um mecanismo externo de governança, o ativismo reflete uma pressão para influenciar as políticas e práticas das empresas, sendo protagonizado tanto por acionistas minoritários (shareholder activists), que utilizam sua posição societária para alcançar seus objetivos (Goranova \& Ryan, 2014), quanto por outros grupos não possuidores de ações, mas que têm algum interesse nas empresas-alvo (stakeholder activists) (Aguilera et al., 2015). Este trabalho se detém a investigar o ativismo de acionistas minoritários, relacionando-o com os elementos antecedentes de GC e performance.

Os conceitos precedentes remetem a fatores diversos como: os tipos de ações realizadas, os diferentes objetivos, as características heterogêneas dos atores e os diversos ambientes regulatórios e de negócios. Trazem também, em seu bojo, elementos comuns à GC, quais sejam: a necessidade de monitorar os administradores e prover incentivos a eles de forma a levar à maximização do valor dos acionistas.

Múltiplas podem ser as abordagens no estudo do ativismo de acionistas, dada sua complexidade. Goranova e Ryan (2014) estruturam décadas de pesquisa sobre o tema, apontando: (a) seus antecedentes, como características das empresas, do ambiente e dos próprios ativistas (Gillan \& Starks, 2003; Judge, Gaur, \& Muller-Kahle, 2010; La Porta et al., 1998); (b) os processos, tais como as ações frente aos administradores e as táticas ativistas (Iliev, Lins, Miller, \& Roth, 2015; McCahery et al., 2015); e (c) os resultados quanto à performance, práticas de governança e reputação (Agrawal, 2012; Cuñat et al., 2012).

Em trabalho mais recente, McNulty e Nordberg (2016) ampliam o entendimento de Goranova e Ryan (2014) ao tratar dos investidores institucionais, estabelecendo o conceito de propriedade ativa e passiva (respectivamente, active e passive ownership). Nesta primeira condição, tais investidores estariam engajados continuamente, tendo uma perspectiva de longo prazo com relação à empresa investida, contrastando com a propriedade passiva, onde os investidores manteriam suas ações, negociariam e eventualmente votariam, porém de forma não deliberada.

As escolhas dos acionistas para agir em garantia de seus interesses têm sido entendidas tradicionalmente como exit, voice, and loyalty, que remete à teoria de Hirschman (1970) (Gillan \& Starks, 1998; Goranova \& Ryan, 2014; McCahery et al., 2015), em seu estudo sobre os mecanismos de recuperação passíveis de serem utilizados pelos atores econômicos para resgatar situações disfuncionais de organizações e da sociedade como um todo. Em situação análoga à perda de qualidade de produtos, em havendo queda de performance das companhias e insatisfação quanto à forma de sua condução, acionistas poderiam optar por vender suas ações (exit) ou se manifestar (voice), como apresentado pelo autor:

Voz é aqui definida como qualquer tentativa de mudar, em vez de escapar de, um estado de coisas censurável, seja por meio de petição individual ou coletiva à administração diretamente responsável, através do apelo a uma autoridade superior com a intenção de forçar uma mudança na gestão, ou através de vários tipos de ações e protestos, incluindo aqueles destinados a mobilizar a opinião pública (Hirschman, 1970, p. 30). 
Assim, tomam-se as ações realizadas nas assembleias de acionistas como uma medida da presença do ativismo, uma vez que se constituem em um representativo meio de demonstração de insatisfação quanto à performance e desejo de modificação das condições dadas (Elst, 2012; Iliev et al., 2015; McNulty \& Nordberg, 2016), evidenciando o engajamento dos acionistas no monitoramento de gestores e manutenção de seus direitos.

Comparado aos estudos mais quantitativos referentes à GC, o ativismo de acionista encontrase em um contexto mais dificultoso, considerando a relativa novidade do tema, sobretudo quando se pretende estudar empresas e/ou países onde os mercados de capitais não são maduros e onde não há uma massa crítica de dados que permita aprofundamento da análise. Assim, observa-se a realização de pesquisas que abordam o tema na perspectiva de análises exploratórias com estatísticas descritivas e modelos mais simples de regressões, sendo os pesquisadores cuidadosos no esclarecimento de sua intenção de não realizar inferências de causalidade entre os termos de análise (Iliev et al., 2015; McCahery et al., 2015).

A literatura acadêmica nacional sobre o tema, embora escassa, tem apresentado recentes contribuições que podem levar ao melhor entendimento do fenômeno. Observamse os trabalhos de Crisóstomo e González (2006), Punsuvo, Kayo e Barros (2007) e Xavier, Marcon, Lana e Silva (2013), que se concentram na análise do possível ativismo dos fundos de pensão em relação à participação societária, destacando sua concentração acionária, sem, no entanto, obter resultados conclusivos.

Alguns estudos ampliaram as análises sobre ativismo de acionistas no mercado brasileiro, dentre os quais destacamos o de Almeida (2017), relativo à atuação de investidores institucionais frente a riscos de expropriação, e o de Vargas (2013), Vargas, Bortolon, Barros e Leal (2017) e Collares (2018), que buscaram evidências sobre tal fenômeno a partir da elaboração de um índice de ativismo de acionistas. Guimarães, Leal, Wanke e Morey (2019), por sua vez, partiram das evidências de ativismo de acionistas para buscar seu impacto na eficiência das empresasalvo encontrando uma relação negativa entre os fatores.

\section{REGRESSÃO QUANTÍLICA (RQ)}

A RQ é um método para a estimação de funções quantílicas condicionais (Koenker \& Hallock, 2001; Koenker, 2005; Wooldridge, 2010).

Diferentemente da regressão pelo método MQO - usual modelo preditor pela média (Hair,
Black, Babin, Anderson, \& Tathan, 2009) com o qual o método desenvolvido por Koenker e Bassett em 1978 é frequentemente comparado (Wooldridge, 2010) -, a RQ permite a discussão da relação das variáveis levando-se em conta a possível heterogeneidade nas respostas associadas às covariáveis (Koenker, 2005). Tal heterogeneidade pode ser observada quando realizado um conjunto de regressões quantílicas (mais facilmente visualizadas a partir de gráficos) e quando são feitas comparações entre quantis, selecionados em função do interesse do pesquisador.

A vantagem mais expressiva da utilização deste método frente à tradicional estimação por MQO é que ele oferece uma compreensão mais ampla da relação entre as variáveis dependentes e independentes (Conyon \& He, 2017), uma vez que apresenta resultados robustos mesmo em bases de dados que contenham outliers, resíduos com características heterocedásticas e distribuições de probabilidade não gaussianas (Prazeres, 2018).

O modelo de regressão quantílica é dado por uma função quantílica, indexada pelo quantil $\tau \in(0,1)$, onde $Q_{y}(\tau \mid x)$ denota o quantil $(\tau)$ de $y$ em função de $x$, conforme a seguinte expressão, cuja tarefa de minimização da função linear é um problema de programação linear (Koenker, 2005):

$$
Q_{y}(\tau \mid x)=x_{i}^{T} \beta
$$

A regressão quantílica em pesquisas empíricas vem se popularizando, uma vez que se procura ampliar a análise dos efeitos das estimativas em diferentes segmentos de uma base de dados analisada (Wooldridge, 2016). Neste sentido, identificamos alguns estudos que, embora tratando de temas como GC, finanças e controle sob diferentes prismas, têm em comum o interesse na explicação das diferentes relações entre suas variáveis dependentes e independentes, quando estas últimas, conforme sua distribuição, afetam diferentemente as primeiras.

Utilizando tal método, o estudo de Conyon e He (2017) permitiu um novo entendimento com relação aos efeitos da diversidade de gênero no conselho de administração das corporações com ações negociadas no mercado americano, uma vez que os resultados, além de sugerirem que a presença feminina impacta positivamente a performance, indicam que este efeito se processa de forma diferenciada ao longo da distribuição. Yensen, Yulu e Paoyu (2017), por sua vez, investigaram a relação entre fatores de governança e de desempenho nas mudanças de participação acionária das empresas estrangeiras no mercado tailandês. 
Dang, Houanti, Le e Vu (2018) aplicaram a RQ encontrando que o percentual de membros independentes no conselho de administração (CA) tem impacto negativo, porém sem significativa diferença entre os quantis estudados, sobre o desempenho (considerado pelo retorno sobre ativos) das empresas presentes na bolsa de valores vietnamita, enquanto esta diferença está presente ao tratarem da relação performance versus dualidade do CEO. Ainda no sentido de apurar a heterogeneidade dos efeitos dos mecanismos de governança sobre o valor de mercado das empresas do mercado de capitais de Kuala Lumpur, Shawatari, Salem, Hussain, Alaeddin e Thabit (2016) empregaram o método em questão e obtiveram resultados estatisticamente significantes em diferentes quantis da amostra.

Chi, Huang e Xie (2015) buscam conciliar resultados conflitantes na literatura confrontando o método convencional (MQO) e o quantílico, com respeito ao custo de empréstimos bancários e a elementos de governança, e argumentam que a heterogeneidade das relações encontradas na pesquisa potencialmente explica as divergências teóricas.

Até onde é dado saber, a utilização da regressão quantílica para estudos do ativismo de acionistas é inexistente, tendo Audretsch, Hülsbeck e Lehmann (2013) tangenciado o tema em seu estudo sobre as famílias como monitores ativos da performance em empresas familiares. Caberia também mencionar Prazeres (2018) ao utilizar o método em seu estudo referente à estrutura de propriedade e o conservadorismo condicional. Desta forma, a aplicação do método sobre o ativismo de acionistas se constitui em uma oportunidade para verificar a relação deste fenômeno e os elementos de governança e desempenho, considerando que haja efeitos diferenciados nos resultados.

\section{MÉTODO}

\section{Dados e variáveis}

Para este estudo utilizou-se base de dados que apresenta o índice de ativismo de acionistas em assembleias (IAAA) de cem empresas de capital aberto, listadas na Brasil, Bolsa, Balcão (B3), que em 2016 apresentaram a maior liquidez em suas ações. Os critérios de seleção da amostra deveram-se: (a) ao entendimento de que o conjunto selecionado era representativo do ambiente de negócios, tendo em vista que, na época, correspondiam a aproximadamente $90 \%$ do total da capitalização de todas as companhias que atuavam na bolsa de valores brasileira; e (b) ao fator exequibilidade, considerando o volume de documentos analisados demandado pela pesquisa documental.
O IAAA é o somatório da frequência de ocorrências de ativismo de acionistas por empresaano dimensionado de forma dicotômica (recebendo valor um se o fenômeno é verificado e zero na sua ausência). As frequências foram identificadas por meio da leitura das 315 atas das assembleias ordinárias e extraordinárias das empresas da amostra, realizadas entre janeiro/2016 e abril/2017. A esse material, coletado por meio de acesso ao sítio da CVM, foi aplicado o método de análise de conteúdo com grades mistas (Neuendorf, 2012), com apoio do software Atlas.ti.

O índice é composto por nove quesitos que correspondem a ações de acionistas para: (a) eleger membros em conselhos de administração e conselhos fiscais; (b) rejeitar propostas da administração; (c) votar contra propostas de administradores; (d) encaminhar suas propostas antes da assembleia; (e) encaminhar suas propostas durante as assembleias; (f) requerer a instituição de conselhos fiscais; (g) solicitar eleições por voto múltiplo ou em separado; (h) aprovar suas próprias propostas; e (i) publicar voto de dissensão. Considerando que o índice é o somatório dos eventos de assembleias que são realizadas em quantidade diferente por cada empresa em cada ano, o resultado pode ser maior que nove por empresa-ano.

As categorias de ativismo que compõem o índice estão fundamentadas teoricamente pela literatura acadêmica sobre o tema (Gillan \& Starks, 1998; 2003; Goranova \& Ryan, 2014; McCahery et al., 2015; Vargas et al., 2017), pela legislação pertinente às sociedades por ação (Lei n. ${ }^{\circ} 6.385,1976$; Lei n. ${ }^{\circ}$ $6.404,1976$; Lei n. $\left.^{\circ} 10.303,2001\right)$ e regulamentos (instruções da CVM n. ${ }^{\circ} 480$ e n. ${ }^{\circ} 481$, datadas de 7 e 17 de dezembro de 2009, respectivamente). O IAAA corresponde à variável dependente da análise econométrica proposta na pesquisa.

Ao primeiro conjunto de dados foram agregadas as informações financeiras e cadastrais das empresas selecionadas, referentes aos exercícios fiscais de 2015 e 2016, obtidas pelo acesso ao banco de dados da Economática ${ }^{\circledR}$. O critério de defasagem dos dados em um ano $(t)$ corresponde à presunção de que as ações de ativismo são reativas ao desempenho das empresas no ano $(t-1)$, sendo sua eventual insatisfação expressa em assembleias posteriores à divulgação dos relatórios financeiros. Assim, o IAAA é associado ao ano da assembleia $(t)$, e indicadores de governança e indicadores financeiros são associados ao ano anterior $(t-1)$.

Os dados foram tratados sob forma de painel. As variáveis explicativas selecionadas para este estudo foram elencadas na Tabela 1, que apresenta descrição, fundamentação teórica e expectativa de relacionamento com o índice de ativismo (IAAA): 
Tabela 1. Descrição das variáveis explicativas.

\begin{tabular}{|c|c|c|c|}
\hline Código & Sinal & Descrição & Fundamento \\
\hline NMN2 & - & $\begin{array}{l}\text { Dummy que recebe valor um, classificando } \\
\text { empresas que estão no nível de GC premium da } \\
\text { listagem da B3 (Novo Mercado e N2) e zero para N1 } \\
\text { e Tradicional. }\end{array}$ & $\begin{array}{l}\text { Empresas com baixa qualidade de governança motivam } \\
\text { ações de ativismo de acionistas (Gillan \& Starks, 2003; } \\
\text { Vargas et al., 2017). }\end{array}$ \\
\hline Ind-CA & - & $\begin{array}{l}\text { Percentual de conselheiros independentes no CA } \\
\text { das empresas da amostra. }\end{array}$ & $\begin{array}{l}\text { Elst (2012) observa fraca relação entre ativismo e eleições } \\
\text { para o CA. Vargas et al. ( } 2017) \text { encontram relação negativa } \\
\text { e sem significância estatística. }\end{array}$ \\
\hline LN_TAM & + & $\begin{array}{l}\text { Logaritmo da Receita Líquida. Uma vez que há } \\
\text { empresas financeiras na base de dados, para elas, o } \\
\text { cálculo teve como base o ativo total. }\end{array}$ & $\begin{array}{l}\text { Judge, Gaur e Muller-Kahle (2010) observaram relação } \\
\text { positiva entre ativismo e tamanho das empresas-alvo } \\
\text { quando ações eram social-driven; quando financial- } \\
\text { driven, não houve resultados significantes. }\end{array}$ \\
\hline QTOBIN & - & $\begin{array}{l}\text { Razão entre o somatório do valor de mercado } \\
\text { das ações e as dívidas, dividido pelo ativo total - } \\
\text { equação simplificada por Chung e Pruitt (1994). }\end{array}$ & $\begin{array}{l}\text { Pereira (2010) e Xavier et al. (2013) sugerem, sem } \\
\text { resultados conclusivos, maior ativismo caso o índice seja } \\
\text { inferior ao esperado pelos acionistas, indicando perda de } \\
\text { valor da empresa. }\end{array}$ \\
\hline ENDIV & - & Razão entre passivo total e ativo total. & $\begin{array}{l}\text { Gillan e Starks (2003) e Vargas et al. (2017) sugerem } \\
\text { haver possível substituição de ações de monitoramento } \\
\text { de acionistas por credores das empresas. }\end{array}$ \\
\hline
\end{tabular}

Nota. Elaborado pela autora.

\section{Especificação do modelo}

Seguindo os objetivos deste estudo, procedeuse a análise multivariada dos dados, tendo como variável dependente o IAAA (por empresa-ano, indexado por $i, t$ ), utilizando-se inicialmente a regressão linear (MQO), expressa a partir da equação:

$$
\text { IAAA }_{i, t}=\alpha+\beta_{1} \text { NMN2 }_{\mathrm{i}, \mathrm{t}-1}+\beta_{2} \text { IND_CA }_{\mathrm{i}, \mathrm{t}-1}+\beta_{3} \mathrm{LN}_{-} \mathrm{TAM}_{\mathrm{i}, \mathrm{t}-1}+\beta_{4} \mathrm{QTOBIN}_{\mathrm{i}, \mathrm{t}-1}+\beta_{5} \mathrm{ENDIV}_{\mathrm{i}, \mathrm{t}-1}+\varepsilon_{\mathrm{i}} .
$$

A regressão quantílica a ser estimada apresenta as mesmas variáveis explicativas da Equação 2 - com o quantil a ser estimado sendo indexado por $\tau$, e expresso pela equação:

$$
\mathrm{Q}_{\tau}\left(\mathrm{IAAA}_{\mathrm{i}, \mathrm{t}}\right)=\propto_{\tau}+\beta_{1 \tau} \mathrm{NMN}_{\mathrm{i}, \mathrm{t}-1}+\beta_{2 \tau} \mathrm{IND}_{-} \mathrm{CA}{ }_{\mathrm{i}, \mathrm{t}-1}+\beta_{3 \tau} \text { LNTAM }_{\mathrm{i}, \mathrm{t}-1}+\beta_{4 \tau} \text { QTOBIN }_{\mathrm{i}, \mathrm{t}-1}+\beta_{5 \tau} \text { ENDIV }_{\mathrm{i}, \mathrm{t}-1}+\varepsilon_{\mathrm{i}}
$$

Para a verificação dos impactos diferenciados das variáveis explicativas sobre o ativismo de acionistas, foi realizada a regressão quantílica, para o intervalo do $10^{\circ}$ ao $90^{\circ}$ percentil, a cada etapa de 0,1 , caracterizandose com isso a distribuição da amostra em 10 decis. Com os recursos oferecidos pelo software utilizado (Gretl), foram gerados gráficos para cada variável da Equação 3, permitindo visualizar a relevância dos resultados apurados no $80^{\circ}$ percentil.

A partir dessa observação, foram realizadas regressões quantílicas em Q50 (mediana da distribuição), Q20 (ponto da distribuição que apresenta $20 \%$ das observações inferiores ao seu IAAA) e Q80 (ponto da distribuição que tem $20 \%$ das observações superiores ao seu IAAA), importando verificar se as diferenças entre os quantis seriam estatisticamente significativas, em intervalos simétricos.

\section{RESULTADOS}

O primeiro resultado obtido refere-se à apuração do IAAA total nos dois períodos observados, fruto do tratamento dicotômico da ocorrência do ativismo, a partir da leitura das atas e documentação acessória pertinente às assembleias das cem empresas selecionadas. A Tabela 2 apresenta o somatório das ocorrências pelos nove quesitos associados ao tema, tendo sido verificada a maior ocorrência em ATIV3 e ATIV1: votações contra a proposta da administração e votações para a eleição de membros para a composição dos conselhos de administração e fiscal, respectivamente. 
Tabela 2. Índice de ativismo de acionistas em assembleias (IAAA) por quesitos (somatório e percentual).

\begin{tabular}{|c|c|c|c|}
\hline Código & Quesitos de ativismo & IAAA & $\%$ \\
\hline ATIV1 & Acionistas elegem membros do CA ou do conselho fiscal (CF) & 111 & $20 \%$ \\
\hline ATIV2 & Acionistas rejeitam (proposta da administração não passa) & 2 & $0 \%$ \\
\hline ATIV3 & Acionistas votam contra, mas não conseguem rejeitar proposta da administração & 257 & $47 \%$ \\
\hline ATIV4 & Acionistas encaminham propostas durante as assembleias & 20 & $4 \%$ \\
\hline ATIV5 & Acionistas encaminham propostas antes das assembleias & 3 & $1 \%$ \\
\hline ATIV6 & Acionistas requerem instituição do CF & 43 & $8 \%$ \\
\hline ATIV7 & Acionistas requerem voto múltiplo para eleição de membros do CA & 67 & $12 \%$ \\
\hline ATIV8 & Acionistas aprovam propostas próprias & 5 & $1 \%$ \\
\hline \multirow[t]{2}{*}{ ATIV9 } & Acionistas publicam voto de dissensão & 43 & $8 \%$ \\
\hline & Total do IAAA das empresas analisadas & 551 & $100 \%$ \\
\hline
\end{tabular}

Nota. O índice de ativismo de acionistas em assembleias (IAAA) foi calculado a partir da análise das atas das assembleias e é uma variável dicotômica que assume o valor um na ocorrência do quesito retratado. A coluna IAAA é o somatório da pontuação para todas as empresas no quesito nos dois anos e a coluna "\%" é o percentual dessa pontuação em relação ao total.

Ao agruparmos os tipos de ativismo em ações associadas aos temas de representatividade em conselhos (ATIV1, ATIV6, ATIV7), atuações sobre as propostas (aprovação das próprias: ATIV4, ATIV5 e ATIV8; rejeição das emitidas pela administração: ATIV2, ATIV3) e manifestação de dissensão (ATIV9), temos a seguinte pontuação, respectivamente: 221 (40\%), 287 (52\%) e 43 (8\%).

O que poderia parecer um equilíbrio entre os dois primeiros canais de acesso para aumento da influência dos acionistas ativistas (eleger conselheiros e agir ativamente na rejeição/aprovação de propostas) revela-se desbalanceado. Considerando estritamente os quesitos ATIV1 e a soma dos quesitos ATIV2 e ATIV8 como ações efetivas - vinculantes no sentido da obrigatoriedade da ação administrativa (a menos que não cumpra com pré-requisitos legais, os conselheiros eleitos serão empossados e propostas vencedoras serão executadas) -, observa-se que representam respectivamente 111 (20\%) e 7 (1\%) das ocorrências. Os resultados, consistentes com os apurados por Vargas (2013), sugerem que o acesso aos conselhos de administração e fiscal pode ter sido favorecido por alterações em estatutos legais e regulamentos, uma vez que permitem aos acionistas minoritários requererem modalidades diferenciadas de votação (por voto múltiplo ou em separado), modificando a dinâmica do processo eleitoral.

A Figura 1 apresenta a distribuição da frequência do IAAA das empresas, onde é possível observar sua assimetria: à direita tem-se 20 empresas que concentram $38 \%$ dos pontos (212 pontos, média de 10,60$)$ enquanto 80 empresas somam 62\% (339 pontos, média de 4,24 ).

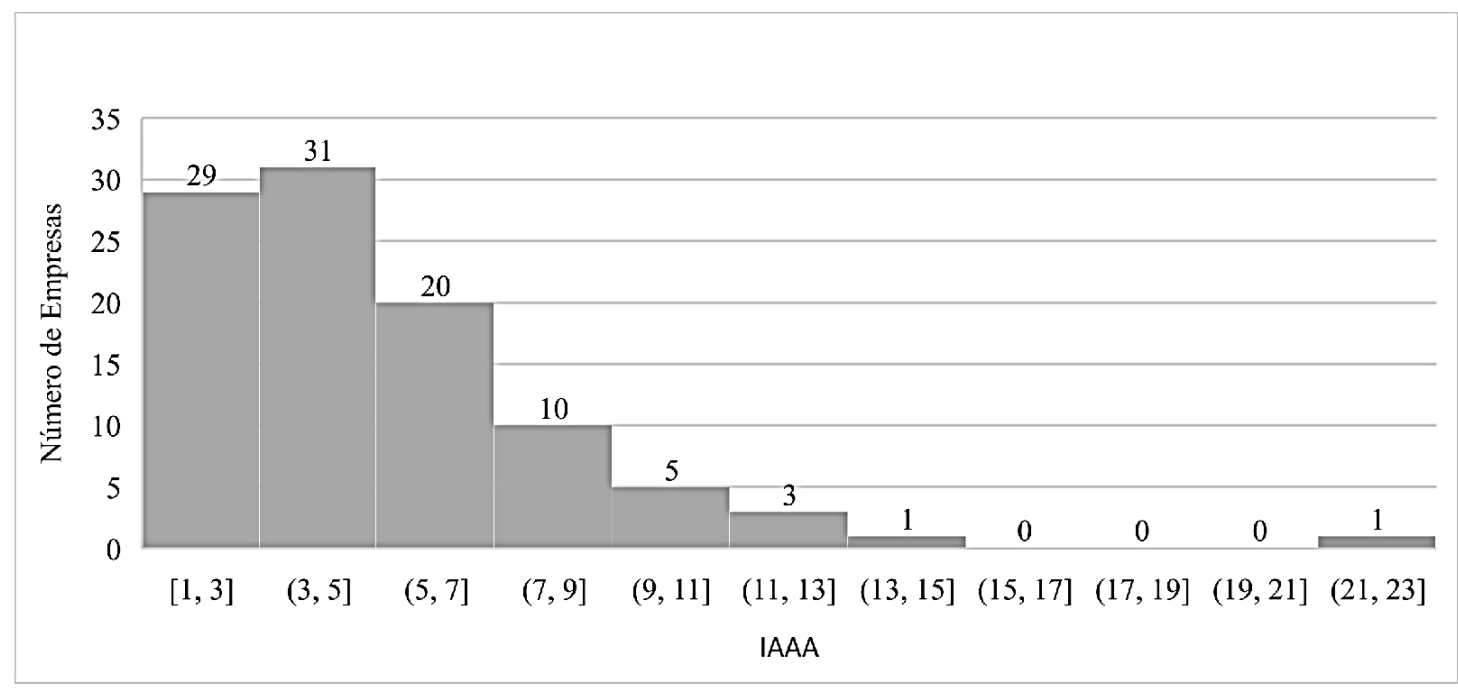

Figura 1. Distribuição de frequência do IAAA das empresas (100). 
A partir deste ponto, visando ao cálculo dos modelos econométricos, o IAAA passou a ser analisado conforme sua ocorrência a cada ano (200 observações).

Como pode ser visto na Tabela 3, a variável IAAA apresenta o valor máximo de 14 (Petrobras-2017) e mínimo de zero (Gol-2016 e Pão de Açúcar-2016). O IND_CA, que corresponde ao percentual de conselheiros independentes no CA, apresenta valor mínimo de zero em 32 observações (correspondendo a 21 empresas pelas 200 observações nos dois anos analisados). As empresas que apresentam maior proporção de independentes são Valid e BMFBovespa $(0,71)$. A variável de desempenho QTOBIN apresenta valores negativos em 38 observações, o que leva a uma média de 0,22 .

Não foi observada colinearidade entre as variáveis do modelo, uma vez que os coeficientes da correlação foram menores que 0,90 (Hair et al., 2009), conforme pode ser visto na Tabela 4.

Tabela 3. Estatística descritiva dos dados.

\begin{tabular}{|c|c|c|c|c|c|c|}
\hline Estatísticas & IAAA & NMN2 & Ind_CA & LN_TAM & ENDIV & QTOBIN \\
\hline Mínimo & 0,00 & 0,00 & 0,00 & 12,89 & 0,10 & $-0,66$ \\
\hline $1^{\circ}$ quartil & 1,00 & 0,00 & 0,14 & 14,55 & 0,48 & 0,06 \\
\hline Mediana & 2,00 & 1,00 & 0,28 & 15,82 & 0,60 & 0,24 \\
\hline Média & 2,76 & 0,74 & 0,29 & 15,83 & 0,61 & 0,22 \\
\hline $3^{\circ}$ quartil & 3,00 & 1,00 & 0,43 & 16,67 & 0,77 & 0,40 \\
\hline Máximo & 14,00 & 1,00 & 0,71 & 21,08 & 1,42 & 1,18 \\
\hline Desvio padrão & 1,90 & 0,44 & 0,20 & 1,71 & 0,22 & 0,26 \\
\hline Observações & 200 & 200 & 200 & 200 & 200 & 200 \\
\hline
\end{tabular}

Nota. IAAA é o índice de ativismo de acionistas em assembleia definido na Tabela 2. As demais variáveis foram definidas na Tabela 1.

Tabela 4. Correlação de Pearson entre variáveis selecionadas.

\begin{tabular}{|c|c|c|c|c|c|c|c|c|c|}
\hline & ATIV & & Ind_CA & & LN_TAM & & ENDIV & & QTOBIN \\
\hline ATIV & 1,000 & & & & & & & & \\
\hline Ind_CA & $-0,318$ & $* * *$ & 1,000 & & & & & & \\
\hline LN_TAM & 0,249 & $* * *$ & $-0,169$ & $* *$ & 1,000 & & & & \\
\hline ENDIV & 0,054 & & $-0,029$ & & 0,485 & $* * *$ & 1,000 & & \\
\hline QTOBIN & 0,230 & $* * *$ & $-0,240$ & $* * *$ & 0,346 & $* * *$ & 0,646 & $* * *$ & 1,000 \\
\hline
\end{tabular}

Nota. IAAA é o índice de ativismo de acionistas em assembleia definido na Tabela 2 . As demais variáveis foram definidas na Tabela $1 . * * * *$ e ** indicam significância ao nível de $1 \%$ e $5 \%$, respectivamente.

Seguindo a proposta deste estudo, foram realizadas regressões para investigar as relações entre o ativismo de acionistas e elementos de governança e de performance. Neste sentido, foram realizadas sequencialmente: (a) a regressão MQO; (b) as regressões quantílicas simultâneas; e (c) as interquantílicas. Os objetivos de cada procedimento corresponderam a, respectivamente: verificar se o método MQO seria adequado ao modelo; verificar se haveria impacto diferenciado entre as variáveis e como seria sua configuração no conjunto das RQ realizadas simultaneamente; e, a partir deste comportamento, selecionar intervalos interquantílicos para que fossem analisados à luz de sua significância estatística. Adicionalmente, para verificação da questão relacionada à causalidade reversa, possível no modelo analisado, foi incorporado ao estudo o modelo de regressão MQO(2) onde foi invertida a classificação das variáveis IAAA e QTOBIN para, respectivamente, explicativa e dependente.

A Tabela 5 apresenta os resultados das regressões MQO e, antecipadamente, os resultados das regressões quantílicas (Q20, Q50 e Q80), que serão discutidos após a apresentação dos resultados das RQs simultâneas, seguindo a sequência lógica do estudo. 
Tabela 5. Resultados dos modelos MQO e quantílicos.

\begin{tabular}{|c|c|c|c|c|c|c|c|c|c|c|c|c|}
\hline \multirow{3}{*}{ Variáveis } & \multirow{3}{*}{$\begin{array}{l}\text { Expec. } \\
\text { do sinal }\end{array}$} & \multirow{3}{*}{$\begin{array}{l}\text { MQO(1) Var. } \\
\text { depend: IAAA }\end{array}$} & \multirow{3}{*}{$\begin{array}{c}\text { MQO(2) Var. } \\
\text { depend: QTOBIN }\end{array}$} & \multicolumn{9}{|c|}{ Variável dependente para regressões quantílicas: IAAA } \\
\hline & & & & \multicolumn{3}{|c|}{ Q20 } & \multicolumn{3}{|c|}{ Q50 } & \multicolumn{3}{|c|}{ Q80 } \\
\hline & & & & \multirow{2}{*}{$\frac{\text { Coef. }}{2,000}$} & \multicolumn{2}{|c|}{ IC $90 \%$} & \multirow{2}{*}{$\begin{array}{r}\text { Coef. } \\
3,000\end{array}$} & \multicolumn{2}{|c|}{ IC $90 \%$} & \multirow{2}{*}{$\begin{array}{c}\text { Coef. } \\
4,424\end{array}$} & \multicolumn{2}{|c|}{ IC $90 \%$} \\
\hline \multirow[t]{2}{*}{ Constante } & & 1,422 & $-0,077$ & & $-0,800$ & 2,000 & & 0,549 & 3,000 & & 0,246 & 7,093 \\
\hline & & $(0,344)$ & $(0,642)$ & & & & & & & & & \\
\hline \multirow[t]{2}{*}{ NMN2 } & - & $-0,587$ & $-0,031$ & $-1,000$ & $-1,000$ & $-0,321 * * *$ & $-1,000$ & $-1,000$ & $-0,230 * * *$ & $-1,114$ & $-2,468$ & $-0,296 * * *$ \\
\hline & & $(0,104)$ & $(0,437)$ & & & & & & & & & \\
\hline \multirow[t]{2}{*}{ Ind_CA } & - & $-1,765^{* *}$ & $-0,222 * * *$ & $-0,000$ & $-1,254$ & $0,000^{* * *}$ & $-0,000$ & $-2,757$ & $0,000^{* * *}$ & $-1,615$ & $-3,499$ & $-0,571^{* * *}$ \\
\hline & & $(0,015)$ & $(0,006)$ & & & & & & & & & \\
\hline \multirow[t]{2}{*}{ LN_TAM } & + & $0,184^{*}$ & $-0,010$ & 0,000 & 0,000 & 0,327 & 0,000 & 0,000 & 0,179 & 0,088 & $-0,079$ & 0,290 \\
\hline & & $(0,056)$ & $(0,373)$ & & & & & & & & & \\
\hline \multirow[t]{2}{*}{ ENDIV } & - & $-1,618^{* *}$ & $0,782 * * *$ & $-0,000$ & $-1,701$ & $0,000 * * *$ & $-0,000$ & $-2,147$ & $0,000 * * *$ & $-1,722$ & $-3,392$ & 0,130 \\
\hline & & $(0,047)$ & $(0,000)$ & & & & & & & & & \\
\hline \multirow[t]{2}{*}{ QTOBIN } & - & $1,604 * *$ & & 0,000 & 0,000 & 0,913 & 0,000 & 0,000 & 2,282 & 1,959 & 0,868 & 3,451 \\
\hline & & $(0,013)$ & & & & & & & & & & \\
\hline \multirow[t]{2}{*}{ IAAA } & - & & $0,020^{* *}$ & & & & & & & & & \\
\hline & & & $(0,013)$ & & & & & & & & & \\
\hline $\mathrm{R}^{2}$ & & 0,185 & 0,487 & & & & & & & & & \\
\hline $\mathrm{R}^{2}$ ajust. & & 0,164 & 0,473 & & & & & & & & & \\
\hline Observ. & & 200 & 200 & 200 & & & 200 & & & 200 & & \\
\hline \multicolumn{13}{|l|}{ Breusch-Pagan } \\
\hline p-valor & & $(0,005)$ & $(0,031)$ & & & & & & & & & \\
\hline Qui-quadrado & & & & 112,961 & & & 112,961 & & & 47,195 & & \\
\hline p-valor & & & & $(0,000)$ & & & $(0,000)$ & & & $(0,000)$ & & \\
\hline \multicolumn{13}{|l|}{ Anova } \\
\hline & \multicolumn{3}{|c|}{$\operatorname{Pr}(>\mathrm{F}) \mathrm{Q} 80$ e $\mathrm{Q} 20$} & & & & & & & $(0,002)^{* * *}$ & & \\
\hline & \multicolumn{3}{|c|}{$\operatorname{Pr}(>\mathrm{F}) \mathrm{Q} 80$ e Q50 } & & & & $(0,001)^{* * *}$ & & & & & \\
\hline & \multicolumn{3}{|c|}{$\operatorname{Pr}(>\mathrm{F}) \mathrm{Q} 50$ e Q20 } & $(0,1)$ & & & & & & & & \\
\hline
\end{tabular}

Nota. Modelos estimados pelo método dos mínimos quadrados ordinários (MQO) e por regressões quantílicas. O IAAA é o índice de ativismo de acionistas em assembleia definido na Tabela 2. Os modelos MQO(1) e MQO(2) têm, respectivamente, o IAAA e o QTOBIN como variáveis dependentes. Os modelos de regressão quantílica consideram os quantis Q20, Q50 e Q80 do IAAA. Q20 corresponde ao ponto com 20\% das observações com menores IAAAs. Q50 corresponde à mediana das observações ordenadas por IAAA. Já Q80 corresponde ao ponto com $20 \%$ das observações com maiores IAAAs. As demais variáveis foram definidas na Tabela 1. IC é o intervalo de confiança. Breusch-Pagan é um teste de heterocedasticidade cuja hipótese nula é que as variâncias dos resíduos são iguais (homocedasticidade). A hipótese nula do teste de qui-quadrado é de normalidade da distribuicão dos resíduos dos modelos das regressões quantílicas. O teste Anova verificou se os efeitos dos regressores são uniformes pelos quantis selecionados, com a significância indicando que não são. ${ }^{* \ldots * *}, * * \mathrm{e}^{*}$ indicam significância ao nível de $1 \%, 5 \%$ e $10 \%$, respectivamente.

Como pode ser observado, os resultados da regressão $\mathrm{MQO}(1)$ apresentam a maioria de suas variáveis significativas e os sinais destas relações dentro das expectativas deste estudo, apresentadas na Tabela 1, exceto na relação entre ativismo de acionistas e QTOBIN. O coeficiente de determinação $\left(\mathrm{R}^{2}\right)$ indica que o modelo explica $19 \%$ do fenômeno, porém o valor-p $(0,005)$ resultante da aplicação do teste de Breusch-Pagan rejeita a hipótese de homocedasticidade, revelando a inadequação do modelo MQO ao conjunto de dados.

No tocante à regressão $\mathrm{MQO}(2)$ - QTOBIN como variável dependente -, observamos significância também em diversas variáveis explicativas, sugerindo a existência de causalidade reversa, um dos clássicos problemas de endogenia relacionados ao tema. Neste sentido, as variáveis de interesse (IAAA e QTOBIN) mostram significância em ambos os modelos. Analogamente ao primeiro modelo, o resultado do teste de Breusch-Pagan $(0,031)$ rejeita a hipótese de homocedasticidade.

Ainda no sentido de verificar se o método MQO seria adequado para a análise da relação entre ativismo de acionistas, GC e desempenho, foram realizados testes no modelo $\mathrm{MQO}(1)$, para verificação de multicolinearidade e adequação da escolha do painel aleatório para análise dos dados. $\mathrm{O}$ teste de variance inflation factor (VIF) apresentou um pequeno valor médio das variáveis $(1,755)$ e o teste de Hausman resultou em valor-p de 0,7017, 
sugerindo, respectivamente, a não existência de multicolinearidade e a adequação do modelo de efeitos aleatórios.

Tendo em vista o objetivo do estudo em verificar o comportamento diferenciado na relação entre o ativismo e os elementos de governança e de desempenho, foram aplicadas regressões para os quantis $($ tau $=\tau)$ cobrindo os intervalos entre $0,1 \mathrm{e}$ 0,9 , com incremento de 0,1 .

Tal comportamento pode ser melhor observado a partir da sua representação gráfica, em que os eixos das abcissas das Figuras 2 e 3 mostram a escala quantílica enquanto os eixos das ordenadas mostram, respectivamente, os efeitos das variáveis Ind_CA e QTOBIN no ativismo de acionistas (IAAA). Em ambas as figuras temos: (a) uma linha tracejada que representa cada $\tau$ estimado; (b) uma área sombreada correspondendo ao intervalo de confiança de $90 \%$
(IC 90\%); e (c) uma linha pontilhada que representa o coeficiente da regressão MQO.

Interpretam-se as estimativas de um ponto quantil como o efeito da mudança de conselheiros independentes no CA (Figura 2) e do índice Q de Tobin (Figura 3) no índice de ativismo, mantendo cada uma das outras variáveis no modelo estatístico fixo.

A relação entre conselheiros independentes no CA e o índice de ativismo apresenta-se decrescente na maioria de seus pontos, indicando que o aumento do número de membros independentes reduz a ocorrência de ativismo, sendo significativo em Q40, Q50, Q60 e Q80 considerando IC 90\%. Os resultados sugerem que a maior presença de conselheiros independentes no CA pode promover a melhoria da GC, minimizando os conflitos de agência e, por conseguinte, reduzindo a ação ativista (Gillan \& Starks, 2003; 2007; McCahery et al., 2015).

Coeficiente em 'Ind_CA'

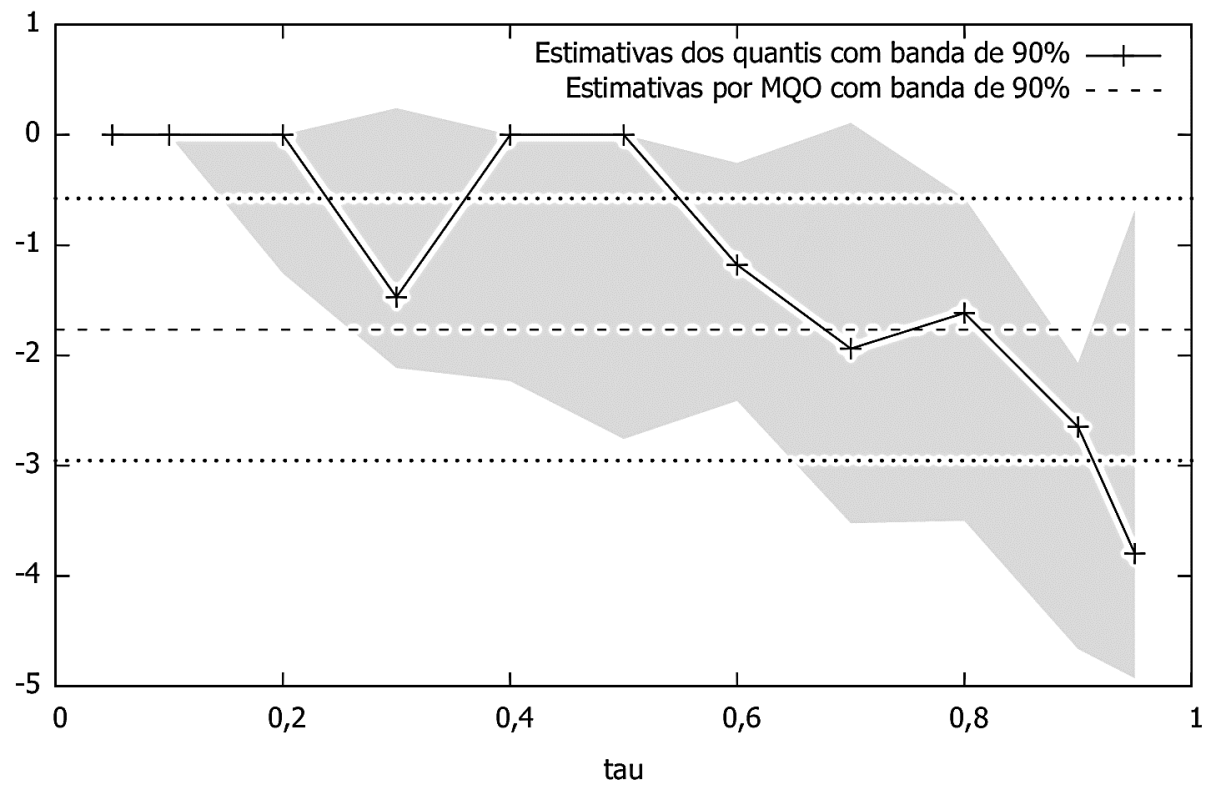

Figura 2. IAAA e Ind_CA: estimativa dos quantis.

O eixo das ordenadas apresenta os coeficientes referentes ao Ind_CA, a proporção de conselheiros independentes no conselho de administração. O eixo das abcissas representa a distribuição quantílica de acordo com o IAAA, o índice de ativismo de acionistas em assembleia definido na Tabela 2.

A relação entre o desempenho (QTOBIN) e o ativismo é positiva e crescente, indicando que a melhora no desempenho poderá levar ao aumento do ativismo de acionistas, porém com resultados não significativos (IC 90\%). Embora o sentido desta relação não tenha sido o esperado, os resultados são compatíveis com os obtidos por Brav, Jiang, Partnoy e Thomas (2008) e por González e Calluzzo (2019). 


\section{Coeficiente em 'QTOBIN'}

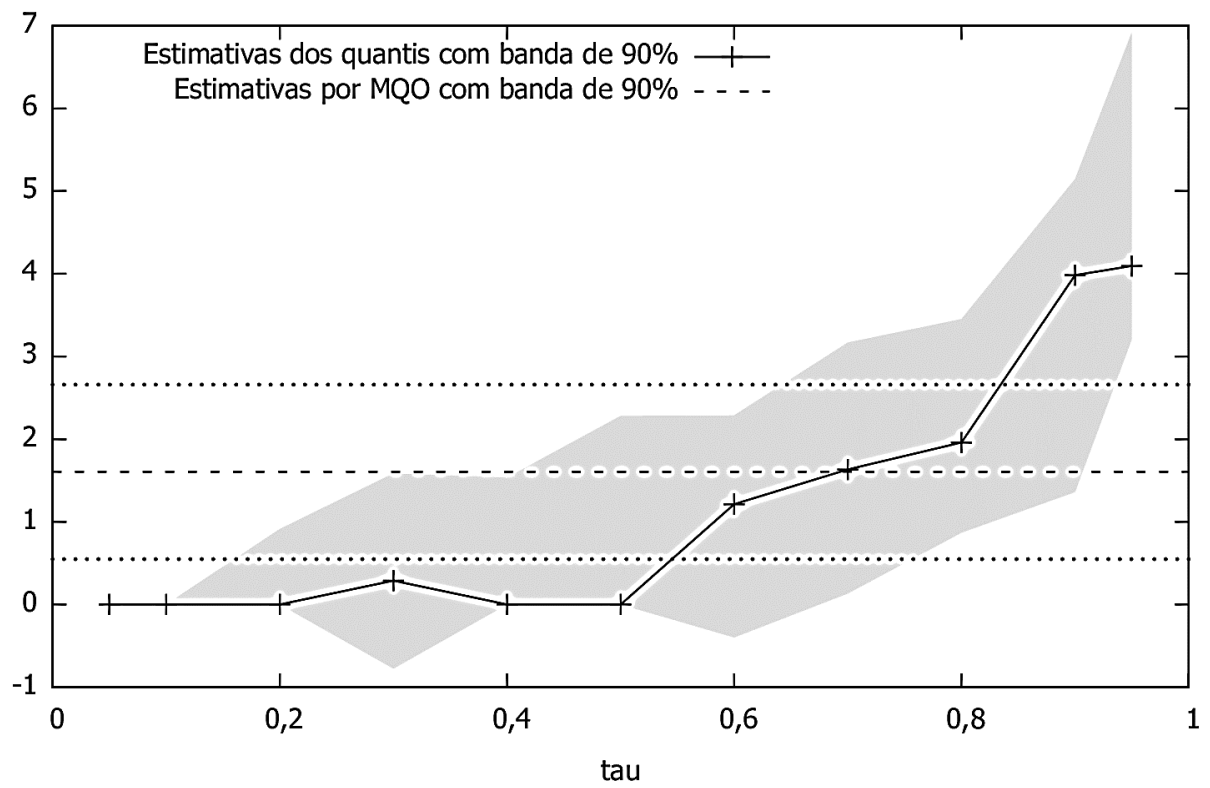

Figura 3. IAAA e QTOBIN: estimativa dos quantis.

O eixo das ordenadas apresenta os coeficientes referentes ao QTOBIN, definido na Tabela 2. O eixo das abcissas representa a distribuição quantílica de acordo com o IAAA, o índice de ativismo de acionistas em assembleia definido na Tabela 2.

Ainda que não tendo sido apresentado o gráfico, os resultados referentes à variável dicotômica NMN2 foram avaliados e mostraram-se significativamente relevantes (IC 90\%) em quantis determinados (Q20, Q50 a Q80) e são negativamente relacionados ao ativismo de acionistas em todo o conjunto de resultados, sugerindo que empresas com melhor nível de GC (pela classificação da B3) tendem a sofrer menor ação de investidores ativistas, conforme observado por Leal, Carvalhalda-Silva e Iervolino (2015) e Vargas et al. (2017).

As demais variáveis explicativas não apresentaram comportamento diferenciado nos diversos quantis calculados.

Os resultados significativos em Q80, observados nas Figuras 2 e 3, provocaram sua análise em destaque, sendo comparados com os resultantes das regressões Q50 (mediana) e Q20 (selecionada por ser o intervalo simétrico), como apresentado na Tabela 5.

Quanto à diferenciação de magnitude do efeito da relação entre ativismo e Ind_CA, recorrese à observação da Tabela 5, que apresenta os coeficientes significativos ao nível de $1 \%$ para as regressões Q20, Q50 e Q80. Desta forma, confirmase a argumentação de que esta variável explicativa impacta diferentemente o ativismo de acionistas, não se podendo rejeitar a Hipótese 1 acerca da relação inversa entre ativismo e qualidade de práticas de GC. Com relação à intensidade do efeito do desempenho sobre o ativismo, observam-se coeficientes sem significância estatística para os mesmos quantis selecionados, não sustentando a Hipótese 2 sobre a relação negativa entre ativismo e desempenho.

Procurou-se então verificar se os efeitos dos regressores são uniformes pelos quantis selecionados, empregando o critério Anova (Kleiber \& Zeileis, 2008). Os resultados mostraram uma diferença significativa entre Q80/Q50 e Q80/ Q20, o que não ocorre entre Q50/Q20.

Como uma forma de avaliação de sensibilidade, o conjunto de dados $(\mathrm{N}=49)$ com IAAA superior ao do oitavo quantil foi aplicado à Equação 1, gerando MQO(3), com as características apresentadas na Tabela 6 . O mesmo conjunto de dados deu origem à regressão MQO(4) pelo método stepwise backward, que elimina variáveis que não contribuem significativamente para o melhor ajuste do modelo (Hair et al., 2009). Os resultados das regressões levaram a um aumento da capacidade explicativa do modelo, observado no $\mathrm{R}^{2}$ ajustado, em 22,7\% (MQO 3) e 24,7\% (MQO 4), sem rejeição da hipótese de homocedasticidade do teste Breusch-Pagan, conforme demonstrado na Tabela 6. 
Ainda testando os modelos, foi aplicado ao conjunto total dos dados $(\mathrm{N}=200)$ o modelo $\mathrm{MQO}(4)$, que melhor explica a regressão aplicada ao conjunto de dados descrito no parágrafo anterior ( $\mathrm{N}=49)$. A última coluna da Tabela 6 - MQO(5) - mostra que este modelo perde capacidade de explicação ( $\mathrm{R}^{2}$ ajustado $=0,76 \%$ ) e assume valor-p $(0,001)$, não afastando a característica heterocedástica dos dados pelo teste BreuschPagan, o que reforça o argumento de inadequação deste método de regressão (MQO) para a base de dados estudada.

Tabela 6. Testes de sensibilidade.

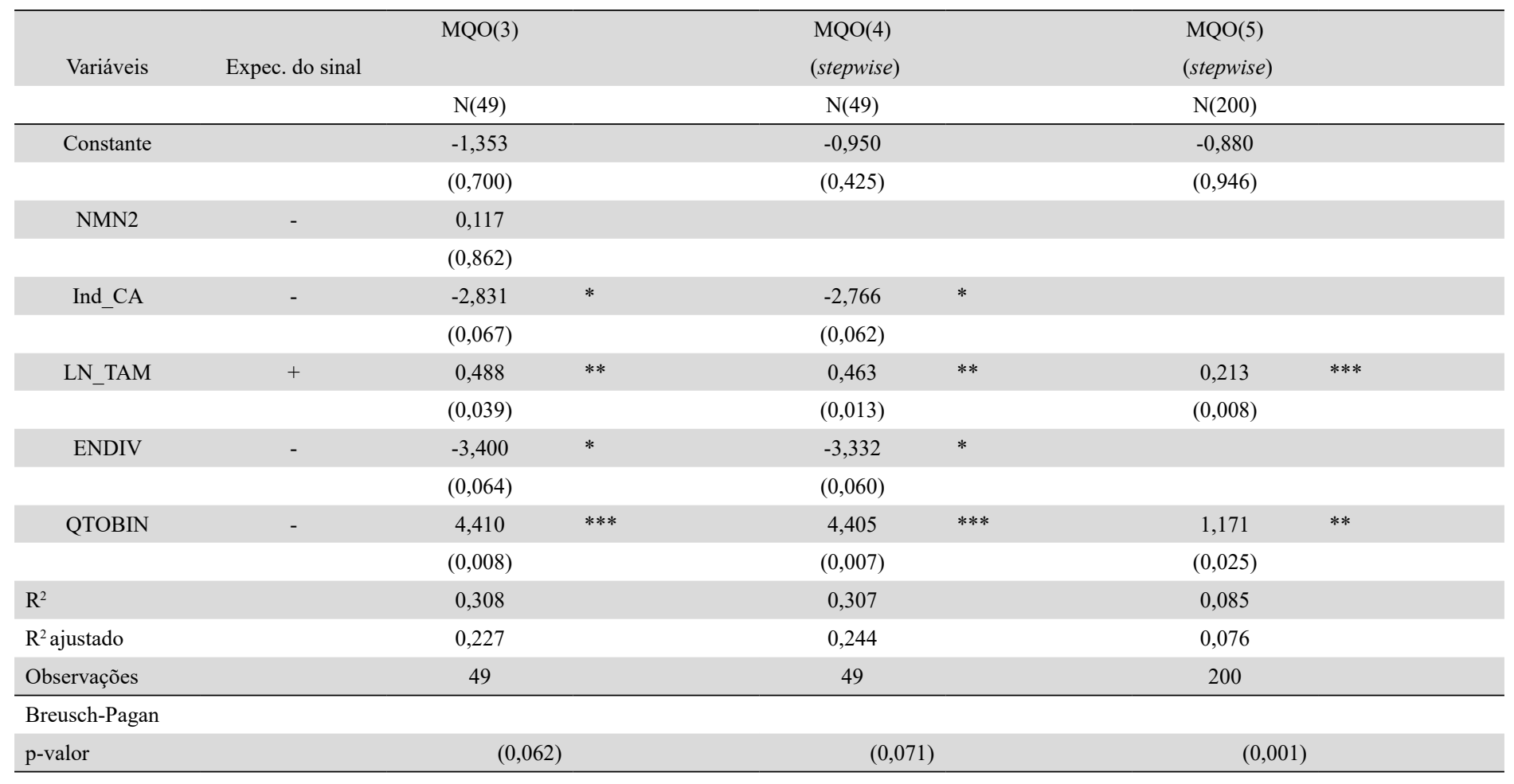

Nota. Modelos estimados pelo método dos mínimos quadrados ordinários (MQO). A variável dependente é o IAAA, que é o índice de ativismo de acionistas em assembleia definido na Tabela 2. Os modelos 3 e 4 foram aplicados ao conjunto de dados que contém $20 \%$ das observações com maiores IAAAs. O modelo 5 foi aplicado a todas as observações da amostra. As demais variáveis foram definidas na Tabela 1 . IC é o intervalo de confiança. Breusch-Pagan é um teste de heterocedasticidade cuja hipótese nula é que as variâncias dos resíduos são iguais (homocedasticidade). $* * * * * *$ e * indicam significância ao nível de $1 \%, 5 \%$ e $10 \%$, respectivamente.

\section{CONCLUSÕES}

A aplicação do método de análise de conteúdo (Neuendorf, 2012), associado ao conjunto de categorias fundamentadas por pesquisas acadêmicas (Gillan \& Starks, 2007; McCahery et al., 2015) voltadas para o ativismo de acionistas sobre o corpo documental (atas e respectivos anexos) de assembleias de acionistas, eventos legítimos que integram e fundamentam as sociedades por ações, permitiu a identificação da presença do fenômeno na amostra selecionada, mensurando-o (Collares, 2018; Leal et al., 2015; Vargas, 2013).

As ocorrências de ativismo de acionistas, tratadas por critério dicotômico, permitiram a elaboração de um índice (IAAA) que somou 551 pontos nas empresas da base de dados, mostrando que a distribuição dos pontos não é homogênea: 20 empresas respondem a $38 \%$ dos pontos (média de 10,60 ) enquanto 80 delas concentram $62 \%$ dos pontos (média de 4,56).

As evidências apontadas dão substância às teorias cuja articulação foi pretendida nesta pesquisa, quais sejam: a presença de conflitos nas organizações, preconizada pela teoria do agente (Jensen \& Meckling, 1976), possivelmente mediada e minimizada pela adoção de melhores práticas de GC (Gillan \& Starks, 1998; 2003; McNulty \& Nordberg, 2016) e pela teoria elaborada por Hirschman (1970) em que os sujeitos podem adotar atitudes de exit, voice, and loyalty, na tentativa de mudar o status quo (Goranova \& Ryan, 2014). A ação ativista de manifestação de insatisfação quanto à condução das 
empresas investidas é entendida com o elemento voice da teoria de Hirschman (1970) e, neste trabalho, foi representada pelos atos dos ativistas durante a assembleia de acionistas nas empresas.

Dada a apuração do índice, procedeu-se a sua análise em função dos elementos de governança e desempenho presentes nas empresas selecionadas, verificando-se o método de regressão mais adequado, considerando que tais variáveis têm diferentes efeitos na distribuição do ativismo. Antes, porém, importa comentar que pesquisas que tratam dos temas relacionados ao ativismo de acionistas encontram recorrentes dificuldades em evidenciálos, na medida em que as relações de causa e efeito não são plenamente verificáveis, como também não o são as ações invisíveis (behind the scenes) (Gillan \& Starks, 2007).

A regressão quantílica - que permite análise dos resultados dos diferentes quantis das regressões (Koenker \& Hallock, 2001; Koenker, 2005) - apresentou-se mais adequada à análise, e a relação entre o ativismo de acionistas e as variáveis explicativas referentes à governança e desempenho mostrou-se mais representativa a partir de seu oitavo decil (Q80).

A relação negativa e significativa encontrada na regressão quantílica entre ativismo e variáveis de GC - nível premium de governança e proporção de conselheiros independentes no CA - vai ao encontro do que argumentam Gillan e Starks $(1998,2003)$ e Vargas et al. (2017), no sentido de que a ocorrência de ativismo diminui à medida que os mecanismos que asseguram melhores práticas de governança sejam eficazes, pois menor será a insatisfação dos acionistas. Dentre essas variáveis de GC, a proporção de conselheiros independentes no CA destaca-se por apresentar significância de forma constante em todos os modelos.

No que tange aos resultados da relação entre variáveis de desempenho e ativismo de acionistas, observa-se que o $Q$ de Tobin não atendeu à expectativa de sinal de seu coeficiente e não demonstrou significância, juntando-se aos resultados inconclusivos obtidos por Pereira (2010) e Xavier et al. (2013) com relação às empresas brasileiras. Considerando que o QTOBIN tem como medida de boa performance um valor próximo a um e que a mediana da amostra é 0,22 , seria esperado que houvesse insatisfação dos acionistas com relação ao desempenho, o que não foi detectado. A análise pela regressão quantílica demonstra que o índice impacta diferentemente o ativismo de acionistas, conforme o quantil observado. Trabalhos futuros poderão melhor estudar a performance a partir da segregação da amostra por grupos que apresentem determinados níveis de desempenho.
O fato de terem sido encontradas perceptíveis evidências no relacionamento entre ativismo de acionistas e fatores de governança e, em paralelo, de não ter sido possível estabelecer de forma satisfatória tal relacionamento com o desempenho, leva à conclusão de que a GC apresenta maior importância do que o desempenho para o ativismo no contexto brasileiro.

Assim como muitas, esta pesquisa também está sujeita a limitações e ressalvas. A primeira é a falta de informações com respeito aos eventos ocorridos nas assembleias: embora haja obrigatoriedade legal, em muitas empresas analisadas as atas e respectivos documentos não estão disponíveis. Além disso, o caráter vago da redação das atas e a ausência de boletim de votos podem ter levado a um índice (IAAA) subdimensionado.

O segundo ponto é a base empírica limitada: a inclusão de outras empresas na base de análise e um período analítico mais longo poderiam levar a resultados mais robustos e ampliariam o poder de explicação e generalização do modelo estudado (RQ), favorecendo a utilização de modelos econométricos, inclusive no tocante à busca de possível causalidade. É possível que haja ações de ativismo entre empresas menos líquidas, por exemplo.

Embora a pesquisa tenha se proposto a estudar o fenômeno das ações que os acionistas ativistas promovem no evento estrutural e legalmente representativo de seu poder de ação - a assembleia -, esta não limita suas possibilidades de atuação. Constitui-se como oportunidade para pesquisas futuras o estudo das ações de ativismo e respectivos efeitos em diferentes canais, sejam públicos (de que forma campanhas ativistas utilizam as diferentes mídias), sejam privados (de que forma ativistas viabilizam suas ações 'invisíveis'), para o alcance de seus objetivos. O estudo da eficácia da atuação do conselheiro independente na melhoria das práticas de GC pode ser um caminho natural para a progressão da pesquisa ora apresentada.

Entende-se que este estudo tenha contribuído para o melhor entendimento do fenômeno. A ampliação das discussões e descobertas sobre o ativismo no meio acadêmico poderá servir de insumo para o ambiente de negócio e para seus reguladores, que, cada um ao seu modo, já enfrentam esta questão como uma realidade.

\section{AGRADECIMENTOS}

A autora agradece a Ricardo P. Câmara Leal pelo inestimável apoio ao trabalho realizado. 


\section{REFERENNCIAS}

Activist Insight. (2019). The activist investing annual review 2019. Retrieved from https://corpgov.law.harvard.edu/ wp-content/uploads/2019/02/AIAnnual_Review2019. pdf

Aggarwal, R., Erel, I., Ferreira, M., \& Matos, P. (2011). Does governance travel around the world? Evidence from institutional investors. Journal of Financial Economics, 100(1), 154-181. https://doi.org/10.1016/j. jfineco.2010.10.018

Agrawal, A. K. (2012) Corporate governance objectives of labor union shareholders: Evidence from proxy voting. The Review of Financial Studies, 25(1), 187-226. https://doi. org/10.1093/rfs/hhr081

Aguilera, R. V., Desender, K., Bednar, M. K. \& Lee, J. H. (2015). Connecting the dots: Bringing external corporate governance into the corporate governance puzzle. Academy of Management Annals, 9(1), 483-573. https:// doi.org/10.5465/19416520.2015.1024503

Aguilera, R. V., Marano, V., \& Haxhi, I. (2019). International corporate governance: A review and opportunities for future research. Journal of International Business Studies, 50, 457-498. https://doi.org/10.1057/s41267019-00232-w

Almeida, A. L. P. (2017). Ativismo de investidores institucionais em empresas de capital aberto no Brasil (Master's Thesis). Universidade Federal do Rio de Janeiro, Instituto COPPEAD de Administração, Rio de Janeiro, RJ, Brazil.

Audretsch, D. B., Hülsbeck, M., \& Lehmann, E. E. (2013) Family as active monitors of firm performance. Journal of Family Business Strategy, 4(2), 118-130. https://doi. org/10.1016/j.jfbs.2013.02.002

Azevedo, R. (2019, April 06). Pagamento da CCR a delatores é contestado. Valor Econômico, Caderno Empresas, Infraestrutura, p. B3.

Berglöf, E., \& Claessens, S. (2006). Enforcement and good corporate governance in developing countries and transition economies. The World Bank Research Observer, 21(1), 123-150. https://doi.org/10.1093/ wbro/lkj005

Brandão, I. F., \& Crisóstomo, V. L. (2015). Ownership concentration and governance quality of brazilian firm. Brazilian Review of Finance, 13(3), 438-469. http:// dx.doi.org/10.12660/rbfin.v13n3.2015.45739

Brav, A., Jiang, W., Partnoy, F., \& Thomas, R. (2008). Hedge fund activism, corporate governance, and firm performance. The Journal of Finance, 63(4), 1729-1775. https://doi. org/10.1111/j.1540-6261.2008.01373.x

Carvalhal, A. (2012). Do shareholder agreements affect market valuation? Evidence from Brazilian listed firms. Journal of Corporate Finance, 18(4), 919-933. https://doi. org/10.1016/j.jcorpfin.2012.04.003

Chi, W., Huang, H., \& Xie, H. (2015). A quantile regression analysis on corporate governance and the cost of bank loans: A research note. Review of Accounting and Finance, 14(1), 2-19. https://doi.org/10.1108/RAF-12-2012-0126
Chung, K. H. \& Pruitt, S. W. (1994). A simple approximation of Tobins's q. Financial Management, 23(3), 70-74. https://doi.org/10.2307/3665623

Collares, M. (2018) Ativismo de acionistas e transações com informação privilegiada no mercado brasileiro de capitais: uma possível relação (Master's Thesis). Universidade Federal Fluminense, Niterói, Rio de Janeiro, Brazil.

Conyon, M. J., \& He, L. (2017) Firm performance and boardroom gender diversity: A quantile regression approach. Journal of Business Research, 79, 198-211. https://doi. org/10.1016/j.jbusres.2017.02.006

Crisóstomo, V., \& González, E. V. (2006). Possível estratégia de ativismo de fundos de pensão no Brasil. Revista de Economia Contemporânea, 10(1), 139-155. http:// dx.doi.org/10.1590/S1415-98482006000100006

Cuñat, V., Gine, M., \& Guadalupe, M. (2012). The vote is cast: The effect of corporate governance on shareholder value. The Journal of Finance, 67(5), 1943-1977. https://doi. org/10.1111/j.1540-6261.2012.01776.x

Dang, A., Houanti, L., Le, N. T., \& Vu, M.-C. (2018). Does corporate governance influence firm performance? Quantile regression evidence from a transactional economy. Applied Economics Letters, 25(14), 984-988. https://doi.org/10.1080/13504851.2017.1390309

Denes, M. R., Karpoff, J. M., \& McWilliams, V. B. (2017). Thirty years of shareholder activism: A survey of empirical research. Journal of Corporate Finance, 44, 405-424. https://doi.org/10.1016/j.jcorpfin.2016.03.005

Elst, C. V. D. (2012). Shareholder rights and shareholder activism: the role of the general meeting of shareholders [Working Paper No. 188/2012]. European Corporate Governance Institute (ECGI). http://dx.doi. org/10.2139/ssrn.2017691

García-Castro, R., Aguilera, R.V., \& Ariño, M. A. (2013). Bundles of firm corporate governance practices: A fuzzy set analysis. Corporate Governance: An International Review. 21(4), 390-407. https://doi.org/10.1111/ corg.12024

García-Meca, E., López-Iturriaga, R., \& Tejerina-Gaite, F. (2017). Institutional investors on boards: Does their behavior influence corporate finance? Journal of Business Ethics, 146(2), 365-382. https://doi.org/10.1007/s10551015-2882-z

Gillan, S., \& Starks, L. T. (1998). A survey of shareholder activism: Motivation and empirical evidence. Contemporary Finance Digest, 2(3), 10-34. Retrieved from https:// ssrn.com/abstract $=211409$

Gillan, S., \& Starks, L. T. (2003). Corporate governance, corporate ownership, and the role of institutional investors: A global perspective. Journal of Applied Finance, 13(2). Retrieved from https://ssrn.com/abstract=480983

Gillan, S., \& Starks, L. T. (2007). The evolution of shareholder activism in the United States. Journal of Applied Finance, 19(1), 55-73. https://doi.org/10.1111/j.17456622.2007.00125.x 
Gompers, P., Ishii, J., \& Metrick, A. (2003). Corporate governance and equity prices. The Quarterly Journal of Economics, $118(1)$, 107-156. https://doi.org/10.1162/00335530360535162

González, T. A., \& Calluzzo, P. (2019). Clustered shareholder activism. Corporate Governance: an International Review, 27(3), 210-225. https://doi.org/10.1111/corg.12271

González, J. S., \& García-Meca, E. (2014). Does corporate governance influence earnings management in latin american markets? Journal of Business Ethics, 121, 419440. https://doi.org/10.1007/s10551-013-1700-8

Goranova, M., \& Ryan, L. V. (2014). Shareholder activism: A multidisciplinary review. Journal of Management, 40(5), 1230-1268. https://doi. org/10.1177/0149206313515519

Goranova, M., \& Ryan, L. V. (2015). Shareholder empowerment: An introduction. In M. Goranova \& L. V. Ryan (Eds), Shareholder empowerment: A new era of corporate governance (Cap. 1, pp. 1-35). London, UK: Palgrave Macmillan.

Guimarães, P., Leal, R. P. C., Wanke, P., \& Morey, M. (2019). Shareholder activism impact on efficiency in Brazil. Corporate Governance, 19(1), 141-157. https://doi. org/10.1108/CG-01-2018-0010

Hair, J. F. Jr., Black, W. C., Babin, J., Anderson, R. E., \& Tathan, R. L. (2009). Análise multivariada de dados. Porto Alegre: Bookman.

Harvard Law School Forum on Corporate Governance and Financial Regulation. (2019). Lazard's Review of Shareholder Activism - Q1 2019. Retrieved from https://www. lazard.com/media/450943/lazards-q1-2019-review-ofshareholder-activism.pdf

Hirschman, A. O. (1970) Exit, voice and loyalty: Responses to decline in firms, organizations and states. Cambridge, USA: Harvard University Press.

Iliev, P., Lins, K. V., Miller, D. P., \& Roth, L. (2015). Shareholder voting and corporate governance around the world. The Review of Financial Studies, 28(8), 2167-2202. https:// doi.org/10.1093/rfs/hhv008

Institutional Shareholder Service (2018). Brazil proxy voting guidelines: Benchmark policy recommendations. Retrieved from https://www.issgovernance.com/file/ policy/active/americas/Brazil-Voting-Guidelines.pdf

Instrução $C V M n^{\circ} 480$, de 07 de dezembro de 2009. (2009). Dispõe sobre o registro de emissões de valores mobiliários admitidos à negociação em mercados regulamentados de valores mobiliários. Com as alterações introduzidas pelas Instruções CVM n ${ }^{\circ} 488 / 10,509 / 11,511 / 11$, $520 / 12$, 525/12, 547/14, 552/14, 561/15, 567/15, $568 / 15, \quad 569 / 15, \quad 583 / 16, \quad 584 / 17, \quad 585 / 17, \quad 586 / 17$ E 588/17. Retrieved from http://www.cvm.gov.br/ legislacao/instrucoes/inst480.html

Instrução CVM no 481, de 17 de dezembro de 2009. (2009). Dispõe sobre informações, pedidos públicos de procuração, participação e votação a distância em assembleias de acionistas. Com as alterações introduzidas pelas Instruções CVM no 552/14, 561/15, 565/15 e 594/17. Retrieved from http://www.cvm.gov.br/legislacao/ instrucoes/inst481.html
Jensen, M. C., \& Meckling, W. H. (1976). Theory of the firm: Managerial behavior, agency costs and ownership structure. Journal of Financial Economics, 3(4), 305360. https://doi.org/10.1016/0304-405X(76)90026-X

Judge, W. Q., Gaur, A., \& Muller-Kahle, M. I. (2010). Antecedents of shareholder activism in target firms: Evidence from a multi-country study. Corporate Governance: An International Review, 18(4), 258-273. https://doi. org/10.1111/j.1467-8683.2010.00797.x

Kleiber, C., \& Zeileis, A. (2008) Applied econometrics with R. New York: Springer-Verlag

Koenker, R. \& Basset, G., Jr. (1978). Regression quantiles. Econometrica, 46(1), p. 33-50. Retrieved from https:// people.eecs.berkeley.edu/ jordan/sail/readings/ koenker-bassett.pdf

Koenker, R., \& Hallock, K. F. (2001). Quantile regression. Journal of Economic Perspectives, 15(4), 143-156. https://doi. org/10.1257/jep.15.4.143

Koenker, R. (2005). Quantile regression. Cambridge, UK: Cambridge University Press.

La Porta, R., Lopez-de-Silanes, F., Shleifer, A., \& Vishny, R. W. (1998). Law and finance. Journal of Political Economy 106(6), 1113-1155. https://doi.org/10.1086/250042

La Porta, R., Lopez-de-Silanes, F., Shleifer, A., \& Vishny, R. W. (2000). Investor protection and corporate governance. Journal of Financial Economics, 58(1-2), 3-27. https:// doi.org/10.1016/S0304-405X(00)00065-9

Leal, R. P. C., Carvalhal-da-Silva, A., \& Iervolino, A. P. (2015). One decade of evolution of corporate governance practices in Brazil. Brazilian Review of Finance, 13(1), 134-161. http://dx.doi.org/10.12660/rbfin.v13n1.2015.50904

Lei $n^{\circ}$ 6.404, de 15 de dezembro de 1976. (1976). Dispõe sobre as sociedades por ações. Diário Oficial da República Federativa do Brasil. Brasília, DF.

Lei $n^{\circ}$ 6.385, de 07 de dezembro de 1976. (1976). Dispõe sobre o mercado de valores mobiliários e cria a comissão de valores mobiliários. Diário Oficial da República Federativa do Brasil. Brasília. DF.

Lei $n^{\circ}$ 10.303, de 31 de outubro de 2001. (2001). Altera e acrescenta dispositivos na Lei no 6.404 , de 15 de dezembro de 1976, que dispõe sobre as Sociedades por Ações, e na Lei no 6.385, de 7 de dezembro de 1976 , que dispõe sobre o mercado de valores mobiliários e cria a comissão de valores mobiliários. Diário Oficial da República Federativa do Brasil. Brasília, DF.

McCahery, J. A, Sautner, Z., \& Starks, L. T. (2015). Behind the scenes: The corporate governance preferences of institutional investors. The Journal of Finance, 71(6), 2905-2932. https://doi.org/10.1111/jofi.12393

McNulty, T., \& Nordberg, D. (2016). Ownership, activism and engagement: Investors as active owners. Corporate Governance: An International Review, 24(3), 364-358. https://doi.org/10.1111/corg.12143

Neuendorf, K. A. (2012) The content analysis Guidebook (2nd ed.). Los Angeles: Sage. 
Pereira, F. (2010). Ativismo dos investidores institucionais, valor, liquidez e governança corporativa: o caso do BNDES no Brasil (Master's Thesis). Universidade Federal do Rio de Janeiro, Instituto COPPEAD de Administração, Rio de Janeiro, RJ, Brazil.

Pinto, M. B., \& Leal, R. P. C. (2013). Ownership concentration, top management and board compensation. Revista de Administração Contemporânea, 17(3), 304-324. http:// dx.doi.org/10.1590/S1415-65552013000300004

Prazeres, R. V. (2018). Relações entre a concentração de propriedade e o conservadorismo condicional nas companhias abertas brasileiras: Uma análise através do modelo de regressão quantílica. Revista Evidenciação Contábil \& Finanças, 6(3), 21-36. https:// doi.org/10.22478/ufpb.2318-1001.2018v6n3.36941

Punsuvo, F. R., Kayo, E. K., \& Barros, L. A. (2007). O ativismo dos fundos de pensão e a qualidade da governança corporativa. Revista de Contabilidade e Finanças, $18(45)$, 63-72. https://doi.org/10.1590/S151970772007000400006

Schiehll, E., Ahmadjian, C., \& Filatotchev, I. (2014). National governance bundles perspective: Understanding the diversity of corporate governance practices at the firm and country levels. Corporate Governance: An International Review, 22(3), 179-184. https://doi. org/10.1111/corg.12067

Schiehll, E., \& Martins, H. C. (2016). Cross-national governance research: A systematic review and assessment. Corporate Governance: An International Review, 24(3), 181-199. https://doi.org/10.1111/corg.12158

Shleifer, A., \& Vishny, R. W. (1997). A survey of corporate governance. The Journal of Finance, 52(2), 737-783. https://doi.org/10.1111/j.1540-6261.1997.tb04820.x

Saito, R., \& Silveira, A. D. M. da (2008). Governança corporativa: Custos de agência e estrutura de propriedade. Revista de Administração de Empresas, 48(2), 79-86. http:// dx.doi.org/10.1590/S0034-75902008000200007

Santos, R. C. dos, Orso, L. É., Lizote, S. A., \& Marcon, R. (2018). Board of directors: The perspective of independents in the performance of private organizations? Evidences in Brazil. Revista de Administração Mackenzie, 19(4), eRAMF180003. http://dx.doi.org/10.1590/16786971/eramf180003

Shawatari, F. A., Salem, M. A., Hussain, H. I., Alaeddin, O., \& Thabit, O. B. (2016). Corporate governance characteristics and valuation: Inferences from quantile regression. Journal of Economics, Finance and Administrative Science, 21(41), 81-88. https://doi. org/10.1016/j.jefas.2016.06.004
Silveira, A. D. M. da, Leal, R. P. C., Carvalhal-da-Silva, A. L., \& de Barros, L. A. B. de C. (2010). Endogeneity of Brazilian corporate governance quality determinants. Corporate Governance, 10(2), 191-202. https://doi. org/10.1108/14720701011035701

Sonza, I. B., \& Kloeckner, G. de O. (2014). Governança em estruturas proprietárias concentradas: Novas evidências para o Brasil. Revista de Administração, 49(2), 322-338. https://doi.org/10.5700/rausp1149

Valadares, S. M., \& Leal, R. P. C. (2000). Ownership and control structure of Brazilian companies. Revista Abante, 3(1), 29-56. Retrieved from https://ideas.repec.org/a/pch/ abante/v3y2000i1p29-56.html

Valenti, G., \& Schincariol, J. (2018, October 03). Acionistas buscam anular acordo com fundador. Valor Econômico, Caderno Empresas, p. B2.

Vargas, L. H. F. (2013). Ativismo de acionistas no mercado acionário brasileiro: Evidências e determinantes em empresas listadas na BM\&FBovespa (Master's Thesis). Universidade Federal do Espírito Santo, Centro de Ciências Jurídicas e Econômicas, Vitória, Espírito Santo, Brazil. Retrieved from http://www.cienciascontabeis. ufes.br/pt-br/pos-graduacao/PPGCC/detalhes-datese?id=6527.

Vargas, L. H. F, Bortolon, P. M., Barros, L. A., \& Leal, R. P. C. (2017). Recent activism initiatives in Brazil. Relatórios COPPEAD, 432. Retrieved from https://pantheon.ufrj. $\mathrm{br} /$ bitstream/11422/2351/1/432.pdf

Wooldridge, J. M. (2010). Econometric analysis of cross section and panel data (2nd ed.). Massachusetts, USA: The MIT Press.

Wooldridge, J. M. (2016). Introductory econometrics: A modern approach (6th ed.). Boston: Cengage Learning.

World Bank Group. (2019). DataBank - World Development Indicators. Retrieved from https://databank. worldbank.org/source/world-developmentindicators? savedlg=1\&l=en\#

Xavier, W. G., Marcon, L., Lana, J., \& Silva, A. (2013, September). Fundos de pensão, ativismo e governança corporativa. Anais do Encontro Nacional da Associação Nacional de Pós-Graduação e Pesquisa em Administração, Rio de Janeiro, RJ, Brasil, 37.

Yensen, N., Yulu, L., \& Paoyu, H. (2017). Foreign institutional investors, shareholding change, and corporate governance. Emerging Markets Finance and Trade, 53(4), 764-775. https://doi.org/10.1080/154049 $6 X .2015 .1105634$ 


\section{Autoria}

\section{Marta Leite Collares*}

Rua Pascoal Lemme, no 355, Ilha do Fundão, 21941-901, Rio de Janeiro, RJ, Brasil.

E-mail: marta.collares@coppead.ufrj.br

(1) https://orcid.org/0000-0003-3972-2599

* Autor Correspondente

\section{Contribuições dos Autores}

$1^{\text {a }}$ autora: Elaboração da pesquisa; revisão de literatura; coleta dos dados; definição do método e aplicação do modelo; análise dos dados e interpretação dos resultados; redação do manuscrito e revisões.

\section{Disponibilidade dos Dados}

Todos os dados e materiais foram disponibilizados publicamente por meio da plataforma Mendeley e podem ser acessados em:

Collares, Marta (2020), "Data for: "Corporate Governance: a major factor in shareholder activism in Brazil " published by RAC - Revista de Administração Contemporânea", Mendeley Data, v1. http://dx.doi.org/10.17632/frxhy2hk94.1

\section{Financiamento}

A autora informou que não houve apoio financeiro para a pesquisa neste artigo.

\section{Conflito de Interesses}

Os autores informaram que não há conflito de interesses.

\section{Direitos Autorais}

A RAC detém os direitos autorais deste conteúdo.

\section{Verificação de Plágio}

A RAC mantém a prática de submeter todos os documentos aprovados para publicação à verificação de plágio, mediante o emprego de ferramentas específicas, e.g.: iThenticate.

\section{Método de Revisão por Pares}

Este conteúdo foi avaliado utilizando o processo de revisão por pares duplo-cego (double-blind peer-review). A divulgação das informações dos pareceristas constantes na primeira página é feita somente após a conclusão do processo avaliativo, e com o consentimento voluntário dos respectivos pareceristas. 